of fine chemicals are unable, or do not find it convenient, to meet the need. The arrangement proposed is that the substances shall be made and supplied on a cost price basis, and it is understood that purchases made in this way will require no special Treasury sanction, being in fact acquisitions to stores. The secretary of the Advisory Research Council is Mr. S. E. Carr, Chemical Society, Burlington House, Piccadilly, London, W.1.

\section{Registration of Chemists}

CoMPULSORY registration on the Central Register of the Ministry of Labour, which was applied last week to engineers, has now been extended to chemists, physicists, and quantity surveyors. The order referred to all possessing a science degree of a university of the British Empire including chemistry or physics and, in certain circumstances, those who passed the corresponding intermediate examination, or have similar standing in these subjects; also to those who have received training as quantity surveyors. These registrations will supplement the names of those already voluntarily on the Central Register.

\section{Physical Problems in Industry}

IN order to assist professional men who in the present emergency find themselves presented with technical problems in applied physics of which they do not happen to have had previous first-hand experience, it has been decided to extend the facilities of the Institute of Physics' panel of consultants. Through this medium inquirers are put into touch with those physicists most likely to be able to offer immediate practical suggestions in any particular case. In the first instance the contact is quite informal; subsequent arrangements are a matter for private agreement between those concerned. The subjects which can be dealt with cover all branches of physics, both pure and applied, including, for example, physical measurements and testing, the design and supply of scientific instruments for special purposes, and the control of processes by physical means.

By acting as a clearing house in this way and supplementing existing official and unofficial organizations, it is hoped to help in the national effort by directing attention to existing solutions of difficulties which, while appearing to be new problems, are often already well-known in other fields. A typical example will serve to illustrate this point. A recent inquiry related to possible means of measuring the flow of certain animal secretions having complex physical properties, which prevented the use of more usual methods. It happens that certain printing inks have somewhat similar properties, and an informal introduction to a physicist in that industry has proved of great assistance. Inquiries about this scheme should be addressed to the Secretary of the Institute of Physics at the University, Reading.

\section{The B.P. Standard for Ipecacuanha}

FURTHer modifications in monographs of the British Pharmacopœia have been effected by way of notice in the Gazette of July 5. The chief one is an alteration in the standard for the alkaloidal content of ipecacuanha. The direction in the B.P. 1932 requires the root to contain not less than 2 per cent of the total alkaloids of ipecacuanha, calculated as emetine, of which not less than two thirds consists of non-phenolic alkaloids, calculated as emetine; the change now made is the substitution of "three fifths" for "two thirds". Although the reduction in the standard is but slight, it will have a marked effect upon the availability of a drug which is regarded by the medical profession as an extremely important one, whether prescribed in the form of Galenical preparations, or as its alkaloid emetine, which is a specific in tropical dysentery. The 1932 test excluded from official recognition large importations of the root from Bahia and Minas Geries, eastern States of Brazil, and virtually restricted the source of the standard drug to the western State of Matto Grosso. With the requirement as to the a!kaloidal content reduced by a fifteenth, a substantial proportion of the shipments from the eastern States of Brazil will now conform to the B.P. standard. Thus the security of ipecacuanha root will be relieved and a reduction in the cost may be expected.

\section{Air Raid Precautions}

Followrng the issue of the popular pamphlet "Your Home as an Air Raid Shelter", of which more than 700,000 copies have been sold, the Ministry of Home Security has now issued a second pamphlet called "Air Raids: What You Must Know : What You Must Do". This pamphlet is a complete 'potted' A.R.P. course for the general public. It tells the ordinary man and woman everything he can need to know for the protection of himself and his family in air raids, and to enable him to help his neighbours. It deals with such subjects as protection against bombs, behaviour during and after a raid, how to deal with incendiary bombs and war gases, and contains a simple first aid course. It tells the householder all about the warning system, how to make repairs to his house after a raid, and contains a wealth of practical information on all these subjects. The book is fully illustrated with photographs and diagrams. It can be obtained through any newsagent, price $3 d$., or price $4 d$., including postage, from the Stationery Office, York House, Kingsway, London, W.C.2. The pamphlet will be invaluable to members of factory and other A.R.P. squads.

\section{Utilization of Aliens in National Work}

SrR John Anderson, Home Secretary, in a written answer to a question in the House of Commons on July 18, stated: "I have already given instructions to the police which I hope will prevent the internment of specialists or 'key' workers engaged in connexion with Government contracts or essential export trade. If in any individual case such a person should nevertheless be interned, it is open to his firm to make representations to the appropriate Government Department, and I am always ready to consider the question of releasing any internee who is certified to me by a Government Department as willing and able to render services of importance to the community." 